Article

\title{
Comparisons of Different Lighting Systems for Horticultural Seedling Production Aimed at Energy Saving
}

\author{
Pedro Garcia-Caparros ${ }^{1}$, Rosa María Chica ${ }^{2}$, Eva María Almansa ${ }^{1}$, Antonio Rull ${ }^{1}$, \\ Lara Alicia Rivas ${ }^{1}$, Antonio García-Buendía ${ }^{2}$, Francisco Javier Barbero ${ }^{3}$ and \\ María Teresa Lao ${ }^{1, *(\mathbb{D})}$
}

1 Agronomy Department of Superior School Engineering, University of Almeria, Agrifood Campus of International Excellence ceiA3, Carretera Sacramento s/n, 04120 La Cañada de San Urbano, Almería, Spain; pedrogar123@hotmail.com (P.G.-C.); almansaeva@gmail.com (E.M.A.); a.rull.rodriguez@gmail.com (A.R.); lararivasona@gmail.com (L.A.R.)

2 Engineering Department of Superior School Engineering, University of Almeria, Agrifood Campus of International Excellence ceiA3, Carretera. Sacramento s/n, 04120 La Cañada de San Urbano, Almería, Spain; rmchica@ual.es (R.M.C.); abuendia@ual.es (A.G.-B.)

3 Applied Physics Department of Superior School Engineering, University of Almeria, Agrifood Campus of International Excellence ceiA3, Carretera. Sacramento s/n, 04120 La Cañada de San Urbano, Almería, Spain; jbarbero@ual.es

* Correspondence: mtlao@ual.es Tel.: +34-950-015876; Fax: +34-950-015939

Received: 30 August 2018; Accepted: 17 September 2018; Published: 19 September 2018

\begin{abstract}
Nowadays, the evaluation of sustainability is an important aspect in the study of agricultural systems and the number of projects and methods for impact assessment of food production systems is increasing. In this work, we initially carried out a survey to know the status of the artificial lighting establishment in horticultural seedling nurseries in southern Spain. Taking into account the data obtained in the survey, we conducted an experiment with different types of fluorescent lamps (TLD-18, CF, TL5, TLD-56), light-emitting diodes (LEDs) and their combinations along with the novelty white LEDs lamps and XTRASUN LEDs to evaluate their technical parameters and spectral light qualities. In addition, the effectiveness of light irradiance (ELI $\left.I_{\text {plant }}\right)$ and the use of irradiance (UI) by cucumber and tomato seedling plants were estimated considering their light absorbance capacity previously analyzed. The results showed that TLD-18 lamps and their combinations, CF and XTRASUN LEDs, had a limited value of energy efficiency (VEEI) $\leq 2$. The lamps essayed with the lowest total irradiance were LEDs $(B, R, V, W)$ and the ones with the highest values were TLD58-6 lamps. The effectiveness of light irradiance (ELI $\mathrm{Plant})$ and the UI were slightly higher in the case of cucumber than that of the tomato for all essayed lamps. Considering the effectiveness of the light irradiance (ELI plant $_{1}$ ), TL5-6 lamps showed the highest values. On the other hand, considering the use of irradiance, XTRASUN LEDs on the mode of vegetative growth (VG) showed the highest values.
\end{abstract}

Keywords: artificial light; electric power; morphogenetically active radiation; nurseries; photosynthetically active radiation; spectral irradiance

\section{Introduction}

Light is one of the most important environmental regulators for the growth of crop species since it provides essential energy input and triggers various signaling pathways for the dynamic growth regulation of crops [1]. In this sense, plant species have evolved photoreceptors to sense 
the light environment and adjust to changing environmental conditions through the modulation of cellular processes [2]. Unique plant photoreceptors respond to changing light quality and quantity through developmental and physiological responses commonly referred to as photomorphogenesis [3]. For instance, blue light is involved in a wide range of plant processes such as phototropism, photomorphogenesis, stomatal opening, photosynthesis, and flowering [4,5]; meanwhile, red light participates in stem elongation, root to shoot ratio, chlorophyll content, and photosynthetic apparatus [6].

Among traditional artificial lighting systems, high-pressure sodium (HPS) and fluorescent lamps (FL) have been most commonly used in plant growth systems [7]. Nevertheless, these lighting systems have several drawbacks such as non-uniformity in spectral quality and an excessive heating that may result in tissue damage when lamps are placed near plants [8].

In this sense, the evolution and performance of LEDs in plant growth systems plays an essential role since they emit wavelengths close to those needed by plant photoreceptors, ultimately achieving an optimal production due to the influence in plant morphology and metabolism [9]. Light-emitting diodes (LEDs) are more energy efficient and versatile than traditional lighting systems but their cost is higher. Nevertheless, the improvement of LEDs production and its maintenance reduce their costs and have all contributed to its establishment as a lighting source [10]. The use of LED light in horticulture has been established in plant tissue or cuttings, culture rooms and growth chambers, greenhouses, and nurseries [11].

The establishment of LEDs instead of traditional artificial lighting systems results in energy saving. For instance, while comparing LEDs with traditional lighting systems, Macias et al. [12] reported that there was a great energy saving, between $41 \%$ and $73 \%$ of power consumption, compared with the technology of that period such as HPS lamps. Similarly, Serrano-Tierz [13] concluded that the replacement of metal halide lights by LEDs luminaries resulted in a high energy saving and an increase of the life span of the luminaires. Moreover, the use of LEDs reduces the disposal of toxic elements such as mercury to the environment [14].

Nowadays, the production of horticultural seedlings in southern Spain totals to around $1,800,000,000$ seedling plants [15]. To produce horticultural seedlings, supplementary artificial lighting has been considered as economically practical since it allows growers to improve profits mainly due to a faster development of plants, therefore improving their sales [16]. In one experiment, Almansa et al. [17] reported that tomato producers in the Mediterranean area used growth chambers with artificial light to reduce the period of production and to achieve better quality plants due to the increase of the root/shoot ratio.

In a recent review concerning the achievement in the field of horticulture with the use of different types of LEDs [8], it can be highlighted that these artificial lighting systems are being used as a complementary source of light in growth chambers and greenhouses, vertical farming systems and in the maintenance of postharvest fruit quality of fruits and vegetables. In addition, there are different studies worldwide regarding the use of LEDs during healing and acclimatization in seedlings in different crops such as tomato [18] and pepper [19]. Nevertheless, there are few references about this topic under nurseries as productions systems in southern Spain; therefore, the aims of this work are: (1) to evaluate technical and spectral irradiance of the different types of FL (TLD, TL5 and CF) commonly used in nurseries, LEDs lamps (blue (B), red (R) and red + blue (violet) (V)) with a high saving energy and their different combinations with FL due to the spectral enrichment, and novel types of LEDs such as white LEDs (W) and XTRASUN LEDs; and (2) to theoretically estimate the potential growth of tomato and cucumber seedlings under the lamps assessed. 


\section{Materials and Methods}

\subsection{Survey Concerning Lighting Sources in Horticultural Nurseries}

Before conducting the experiment, we carried out a survey in local horticultural seedling nurseries (50 enterprises) (Figure 1) in southern Spain to determine which was the degree of lighting establishment in these nurseries as well as the main spectral characteristics of the lamps used for horticultural seedling production. The spectral quality data of each nursery was registered using a luxometer (GOSSEN MAVOLUX model 5032C USB; Casella., Madrid, Spain).

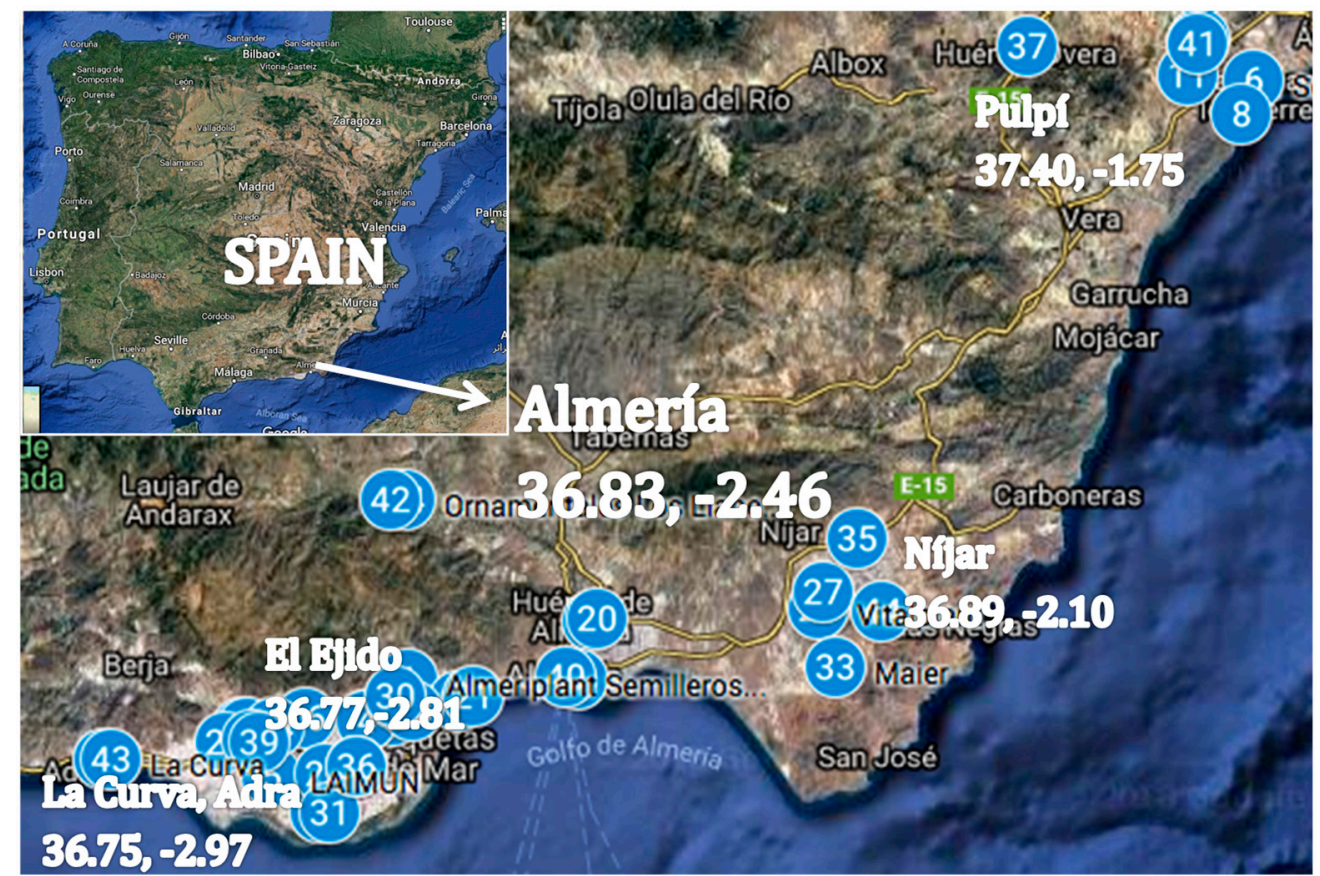

Figure 1. Local horticultural seedling nurseries surveyed in Almería (Spain).

\subsection{Technical Parameters of the Lamps}

The characterization of the lamps assessed in this experiment are shown in Table 1.

Table 1. Types of lamps, characteristics, model, and company of the lamps assessed in the experiment.

\begin{tabular}{ccc}
\hline Lamps & Characteristics & Model and Company \\
TLD & $\begin{array}{c}\text { Fluorescent TLD (Standard lamps with } \\
\text { reduced size tubes of 26 mm diameter) } \\
\text { of } 18 \mathrm{~W} \text { and } 58 \mathrm{~W}\end{array}$ & $\begin{array}{c}\text { Light Philips TCS097, Philips Lighting } \\
\text { Spain, Madrid, Spain }\end{array}$ \\
TL5 & $\begin{array}{c}\text { Standard long tubes with a nominal } \\
\text { diameter of 5/8 inch }\end{array}$ & $\begin{array}{c}\text { High Efficiency Fluorescent TL5 35 W, } \\
\text { MAXOS 4M691, Philips Lighting Spain, } \\
\text { Madrid, Spain }\end{array}$ \\
\hline CF & $\begin{array}{c}\text { Compact fluorescent lamps, PL } \\
\text { Electronic 23 W/840 }\end{array}$ & Philips Lighting Spain, Madrid, Spain \\
\hline LEDs & $\begin{array}{c}\text { ALUM luminaire 40.25 LED SMD RGB } \\
\text { controlled with a DN-RGB FIBER } \\
\text { LIGHT console }\end{array}$ & \\
\hline White LEDs & ALUM luminaire 40.25 LED SMD RGB & \\
\hline XTRASUN LEDs & 2 LEDs conversion antennas, 140 W & Prohydroponics, Greensburg, PA, USA. \\
\hline
\end{tabular}


Twenty-seven combinations between FL and LEDs (blue, red, and violet) were assessed. On the other hand, the choice of white LEDs and XTRASUN LEDs was mainly due to the novelty of these lighting systems sources. In the case of XTRASUN LEDs, it is an equipment that allows the combination of LEDs in order to satisfy the need for light established for plant development in different phenological stages which are set up as programs and also the equipment set-definition program related to the use of five channels: general growth (GG), vegetative growth (VG), flowering period (FP), ultraviolet (UV) and infrared (IR) (Table 2).

For each lighting source of the 27 combinations, white LEDs and XTRASUN LEDs, luminous flux $(\Phi)$ (expressed in $1 \mathrm{~m}$ ) and the total electric power $(\mathrm{P})$ (expressed in $\mathrm{W}$ ) were all recorded. Then, with these measurements we determined the luminous efficacy $(\eta)$ (expressed in $1 \mathrm{~m} \mathrm{~W}^{-1}$ ) using Equation (1). The minimum illumination level (Ev) was calculated dividing the value of $\Phi$ by the surface (S) $\left(1.2 \mathrm{~m}^{2}\right.$ ) (expressed in lx) and the limit value of energy efficiency (VEEI) (expressed in $\mathrm{W} \mathrm{m}^{-2}$ ) was then calculated using Equation (2) following the methodology established by Hidalgo et al. [20].

$$
\begin{gathered}
\eta=\phi / P \\
\text { VEEI }=(\mathrm{P} * 100) /(\mathrm{S} * \text { Em })
\end{gathered}
$$

\subsection{Spectral Irradiance of Lamps}

The spectral distribution scans were recorded at 300-1100 nm with 1-nm steps of the different lamps tested with a calibrated spectroradiometer (LI-COR 1800, Lincoln, NE, USA) at the distance of $45 \mathrm{~cm}$ below to the lamps. With these measurements, the spectral irradiance of each lamp was assessed following the methodology established by Baille et al. [21].

\subsection{Absorbance of Seedling Plants}

Seedling plants of three cultivars of tomato (Mayoral, Creativo and Torry) and three cultivars of cucumber (Jungla, Litoral, and Valle) were grown in a local horticultural seedling nursery (average temperature of $26^{\circ} \mathrm{C}$ and relative humidity of $70 \%$ during the growing period). The radiometric determinations of transmittance (\%Tr) and reflectance (\%Re) of leaves of both seedling plants were measured by an integrating sphere using a calibrated spectroradiometer (LI-COR 1800, Lincoln, NE, USA) in a laboratory in the University of Almeria $\left(36^{\circ} 49^{\prime} \mathrm{N}, 2^{\circ} 24^{\prime} \mathrm{W}\right)$. Measurements were taken in six plants (one replication per plant) per cultivar and species.

The percentage of leaf absorbance $(\% \mathrm{Ab})$ at each wavelength of leaves was obtained using Equation (3):

$$
\% \operatorname{Ab}(\lambda)=100-(\% \operatorname{Tr}(\lambda)+\% \operatorname{Re}(\lambda))
$$

Then, the effectiveness of light irradiance ( $\left(\mathrm{ELI}_{\text {plant }}\right)$ of the different types of lamps assessed on cucumber and tomato leaves was calculated using Equation (4):

$$
\operatorname{ELI}_{\text {plant }}=\mathrm{I}(\lambda) \times \% \mathrm{Ab}(\lambda)
$$

where $\mathrm{I}(\lambda)$ : irradiance at $\lambda\left(\mathrm{W} \mathrm{m}^{-2}\right)$.

Finally, the use of irradiance (UI) in tomato and cucumber was calculated using Equation (5):

$$
\mathrm{UI}=\mathrm{ELI}_{\text {plant }} \times 100 / \text { Itotal }
$$

where Itotal is total irradiance $\left(\mathrm{W} \mathrm{m}^{-2}\right)$. 


\section{Results and Discussion}

\subsection{Current Status of Lighting Establishment in Horticultural Seedling Production}

The different enterprises assessed (50) were located in four different areas with the following geographic coordinates: La Curva $(36.75,-2.97)$, El Ejido (36.77, -2.81), Níjar (36.89, -2.10) and Pulpí $(37.40,-1.75)$. The facilities of the nurseries were multi-tunnel greenhouses and the horticultural crops were the following: tomato, pepper, cucumber, zucchini, eggplant, green beans, melon, watermelon, and lettuce. The data obtained revealed that only $8 \%$ of the total nurseries surveyed used artificial lighting in the first culture period in crop chamber, to improve the uniform and increase growth of the seedling plants. The artificial lighting systems used were FL model TLD (36/58 W) (standard lamps with reduced size tubes of $26 \mathrm{~mm}$ diameter) with an average light intensity from 1600 to 4000 lux. The assessment of the data obtained in the survey allow us to give recommendations about the sorts of lamps and spectral quality needed in this horticultural technology.

The low level of establishment of complementary lighting sources in nurseries in southern Spain can be due to the high level of sunny hours in this area as reported by Castilla and Prados [22]. On the other hand, the use of FL model TLD by nurseries was related to the low cost of these lighting sources and the ease handling as reported the owners of the nurseries surveyed, although the efficiency of these lighting sources was very low. Moreover, the lack of information between nursery growers about the possibilities of the establishment of other lighting sources resulted in the use of the same lighting systems between them. To improve the knowledge of the effects of TLD lamps in horticultural seedlings, Almansa et al. [23] carried out an experiment with these light sources in tomato seedlings reporting a growth enhancement and uniformity.

\subsection{Technical Parameters of the Lamps}

The use of LEDs as complementary light sources did not result in significant changes of luminous flux $(\Phi)$ and minimum illumination level (Em) values in all the lamps assessed. Nevertheless, the addition of LEDs in all the lamps resulted in an increase of the total electric power (P). This increase of total electric power resulted in a decrease of the luminous efficacy $(\eta)$ and an increase of the limit value of energy efficiency (VEEI) compared to the case of lamps without LEDs incorporation. Lamps of TL5-2 with the addition of LEDs showed the highest values of VEEI. Regarding LEDs, it is necessary to point out that white LEDs (new lighting sources) showed the highest values of $\Phi$ and $\eta$ compared to the other LEDs assessed in the experiment and the lowest value of VEEI. Moreover, the combination of red and blue LEDs (LEDs V) resulted in a higher value of luminous efficacy ( $\eta$ ) and a lower limit value of energy efficiency (VEEI) compared with the red and blue LEDs separately. The main technical parameters of XTRASUN LED were a luminous efficacy $(\eta)$ around 50 and a VEEI value of 2.0. From an energy efficiency point of view, it is necessary to highlight that TLD-18 lamps and their combinations, CF and XTRASUN LEDs were the most effective among the sources of light assessed with lower values of VEEI (Table 2), with values lower than 3.5 as proposed by the Spanish Technical Building Code (CTE) (2006) [24].

The range of luminous efficacy in all the lighting sources assessed in our experiment ranged from 1.3 to $75 \mathrm{~lm} \mathrm{~W}^{-1}$, being lower than the values reported by other researchers who obtained luminous efficacies greater than $130 \mathrm{~lm} \mathrm{~W}^{-1}$ in different experiments with different lighting sources [25,26]. Similarly, the values of luminous efficacy in LEDs in our experiment were very low compared to the values reported by other researchers in different experiments $[27,28]$.

As far as the limit values of energy efficiency were concerned, it is necessary to point out that the values registered in lamps combined with LEDs in our experiment were lower than the values reported by Almansa [7], with values around 9. Moreover, the high values of VEEI in LEDs can be related to the increase of light technology during the last ten years. 
Table 2. Technical parameters of the lamps tested: luminous flux $(\Phi)$, total electric power $(P)$, luminous efficacy $(\eta)$, minimum illumination level (Em) and limit value of energy efficiency (VEEI).

\begin{tabular}{|c|c|c|c|c|c|c|c|}
\hline Test & Lamp Type & Lamp Description & $\Phi(\operatorname{lm})$ & $P(W)$ & $\eta\left(\operatorname{lm} W^{-1}\right)$ & Em (lx) & VEEI $\left(\mathrm{W} \mathrm{m}^{-2}\right)$ \\
\hline T1:TLD-18 & TLD $18 \mathrm{~W} / 830$ & 6 & 8100 & 108 & 75.0 & 6750 & 1.3 \\
\hline T2:TLD-18LED-B & TLD 18 W/830 + LED-B & $6+4$ Blue LEDs modules & 8148 & 144 & 56.6 & 6790 & 1.8 \\
\hline T3:TLD-18LED-R & TLD 18 W/830 + LED-R & $6+4$ Red LEDs modules & 8207 & 144 & 57.0 & 6839 & 1.8 \\
\hline T4:TLD-18LED-V & TLD 18 W/830 + LED-V & $6+4$ Violet LEDs modules & 8239 & 144 & 57.2 & 6865 & 1.7 \\
\hline T5:CF & CF $23 \mathrm{~W} / 840$ & 4 & 5300 & 92 & 57.6 & 4417 & 1.7 \\
\hline T6:CF-LED-B & CF $23 \mathrm{~W} / 840+$ LED-B & $4+4$ Blue LEDs modules & 5348 & 128 & 41.8 & 4457 & 2.4 \\
\hline T7:CF-LED-R & CF 23 W/840 + LED-R & $4+4$ Red LEDs modules & 5407 & 128 & 42.2 & 4506 & 2.4 \\
\hline T8:CF-LED-V & CF 23 W/840 + LED-V & $4+4$ Violet LEDs modules & 5439 & 128 & 42.5 & 4532 & 2.4 \\
\hline T9:TL5-6 & TL5-35 W/830 & 6 & 9900 & 210 & 47.1 & 8250 & 2.1 \\
\hline T10:TL5-6-LED-B & TL5-35 W/830 + LED-B & $6+4$ Blue LEDs modules & 9948 & 246 & 40.4 & 8290 & 2.5 \\
\hline T11:TL5-6-LED-R & TL5-35 W/830 + LED-R & $6+4$ Red LEDs modules & 10,007 & 246 & 40.7 & 8340 & 2.5 \\
\hline T12:TL5-6-LED-V & TL5-35 W/830 + LED-V & $6+4$ Violet LEDs modules & 10,039 & 246 & 41.2 & 8365 & 2.5 \\
\hline T13:TL5-2 & TL5-35 W/830 & 2 & 3300 & 70 & 47.1 & 2750 & 2.1 \\
\hline T14:TL5-2-LED-B & TL5-35 W/830 + LED-B & $2+4$ Blue LEDs modules & 3348 & 106 & 31.6 & 2790 & 3.2 \\
\hline T15:TL5-2-LED-R & TL5-35 W/830 + LED-R & $2+4$ Red LEDs modules & 3407 & 106 & 32.1 & 2840 & 3.1 \\
\hline T16:TL5-2-LED-V & TL5-35 W/830 + LED-V & $2+4$ Violet LEDs modules & 3439 & 106 & 32.4 & 2865 & 3.1 \\
\hline T17:TLD-58-2 & TLD $58 \mathrm{~W} / 840$ & 2 & 5200 & 116 & 44.8 & 4333 & 2.2 \\
\hline T18:TLD-58-2LED-B & TLD 58 W/840 + LED-B & $2+4$ Blue LEDs modules & 5248 & 152 & 34.5 & 4373 & 2.9 \\
\hline T19:TLD-58-2LED-R & TLD 58 W/840 + LED-R & $2+4$ Red LEDs modules & 5307 & 152 & 34.9 & 4423 & 2.9 \\
\hline T20:TLD-58-2LED-V & TLD 58 W/840 + LED-V & $2+4$ Violet LEDs modules & 5339 & 152 & 35.1 & 4449 & 2.8 \\
\hline T21:TLD-58-6 & TLD $58 \mathrm{~W} / 840$ & 6 & 15,600 & 348 & 44.8 & 13,000 & 2.2 \\
\hline T22:TLD-58-6LED-B & TLD 58 W/840 + LED-B & $6+4$ Blue LEDs modules & 15,648 & 384 & 40.8 & 13,040 & 2.5 \\
\hline T23:TLD-58-6LED-R & TLD 58 W/840 + LED-R & $6+4$ Red LEDs modules & 15,707 & 384 & 40.9 & 13,090 & 2.4 \\
\hline T24:TLD-58-6LED-V & TLD 58 W/840 + LED-V & $6+4$ Violet LEDs modules & 15,738 & 384 & 41.0 & 13,115 & 2.4 \\
\hline T25:LED-B & LED-RGB-28 & 4Blue LEDs modules & 48 & 36 & 1.3 & 40 & 74.9 \\
\hline T26:LED-R & LED-RGB-28 & 4Red LEDs modules & 107 & 36 & 3.0 & 90 & 33.5 \\
\hline T27:LED-V & LED-RGB-28 & 4Violet LEDs modules & 139 & 36 & 3.8 & 115 & 26.0 \\
\hline \multirow{2}{*}{$\begin{array}{c}\text { T28:LED-W } \\
\text { T29:XTRASUN } \\
\text { LED }\end{array}$} & \multirow[t]{2}{*}{ LED-RGB-28 } & \multirow[t]{2}{*}{ 4White LEDs modules } & 254 & 36 & 7.1 & 1017 & 3.0 \\
\hline & & & 6938 & 140 & 49.6 & 5781.8 & 2.0 \\
\hline
\end{tabular}




\subsection{Spectral Irradiance of Lamps}

FL assessed showed common peaks at the following wavelengths: 436, 486, 544, 580, 612, 704 and $1010 \mathrm{~nm}$. In addition, in some lamps, there was a pick in ultraviolet region $(364 \mathrm{~nm})$. Regarding LEDs, blue LEDs showed a peak at $470 \mathrm{~nm}$, red LEDs at 636 and blue + red and white LEDS at 470 and $636 \mathrm{~nm}$, respectively. The different stages in XTRASUN LEDs assessed were characterized as follows: GG showed two main peaks at 450 and $660 \mathrm{~nm}, \mathrm{VG}$ at 430 and $660 \mathrm{~nm}$, FP at $660 \mathrm{~nm}$, whereas the ultraviolet (UV) had three main peaks at 405, 460 and $590 \mathrm{~nm}$ and the infrared (IR) at 660 and $745 \mathrm{~nm}$ (Figure 2).

The main peaks observed in the different combinations of lamps and LEDs assessed revealed that they were in the photosynthetically active radiation (PAR) range, so they might affect the photomorphological aspects of the plant along with its development [29]. 

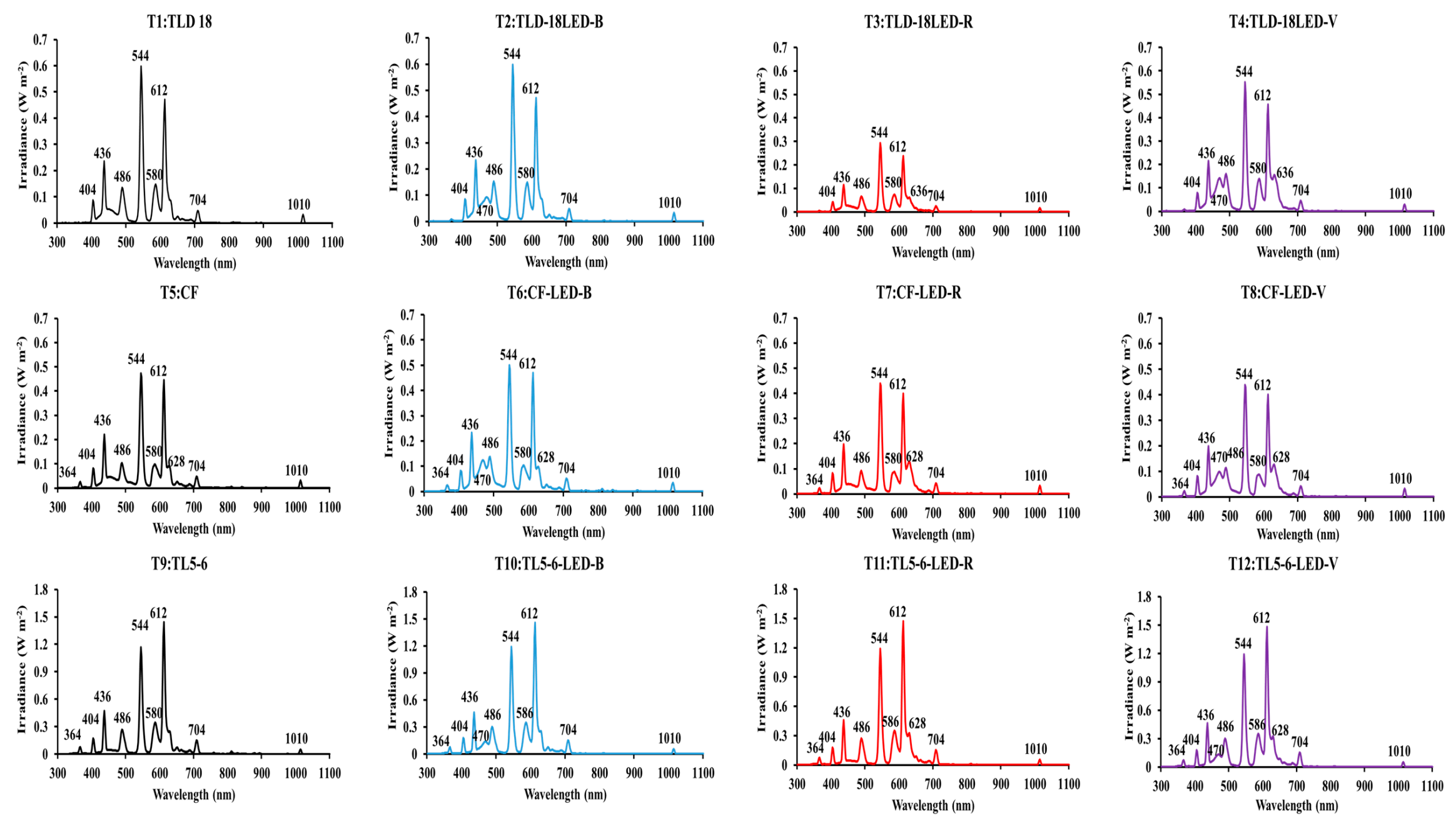

Figure 2. Cont. 

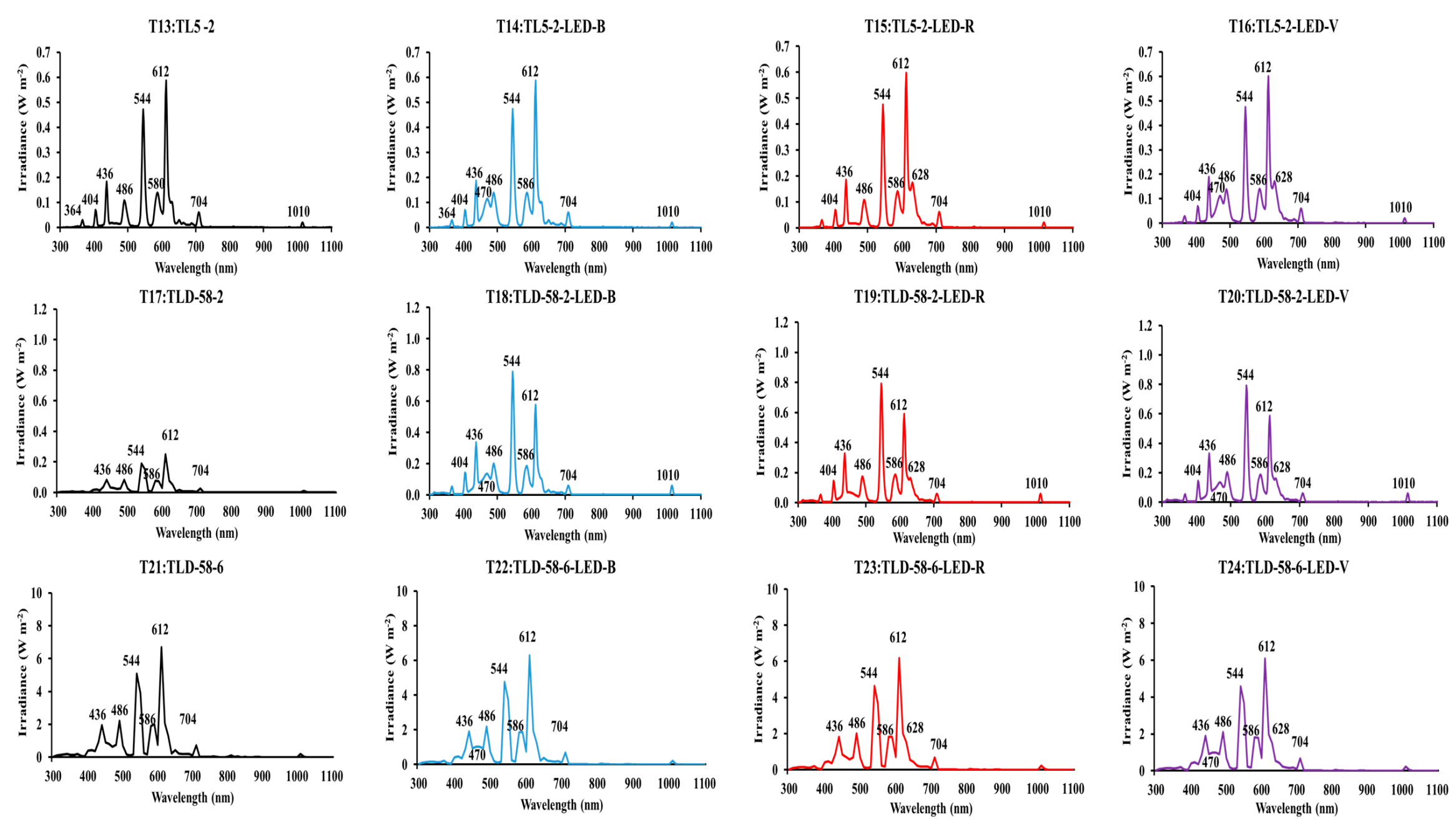

Figure 2. Cont. 

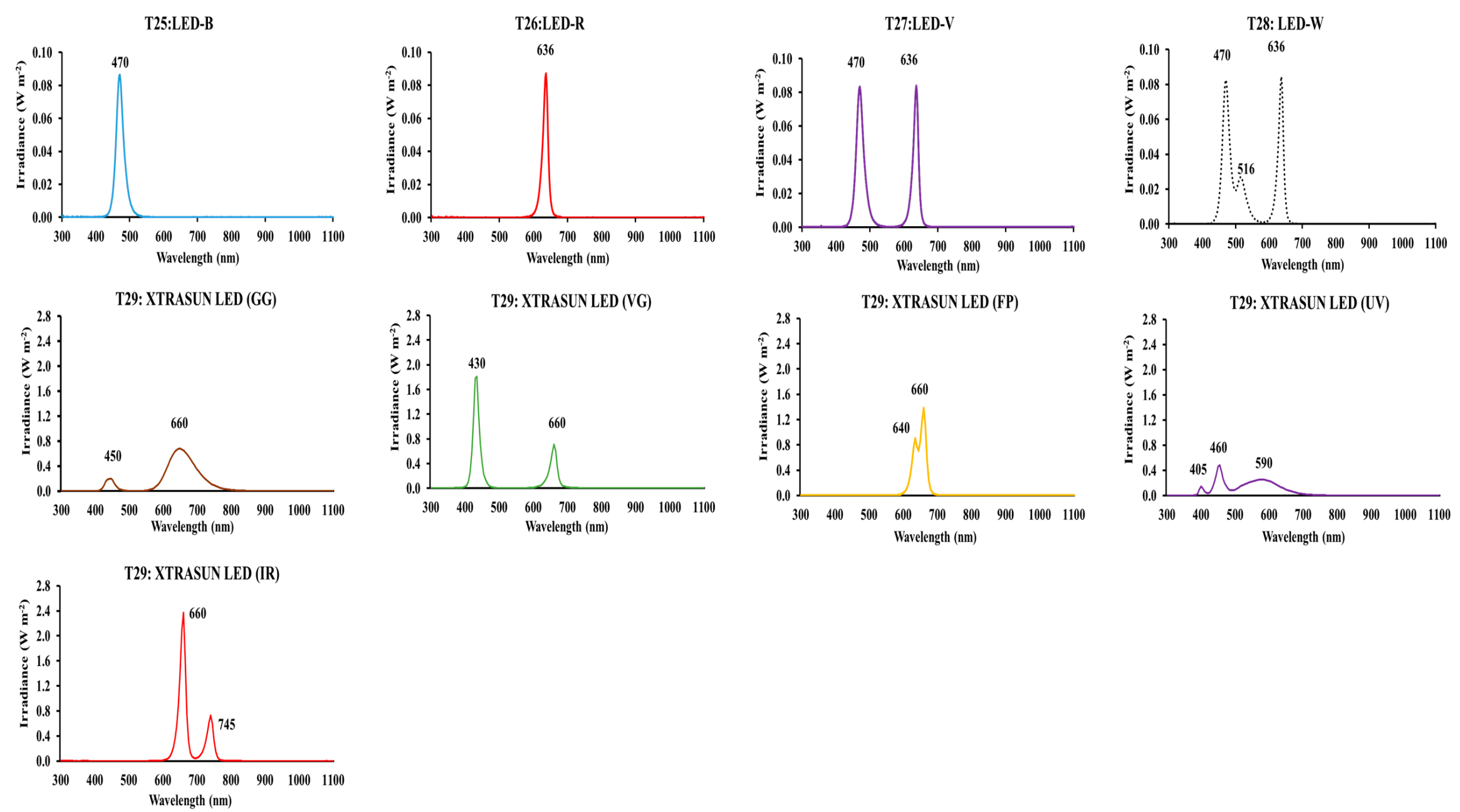

Figure 2. Spectral irradiance of different fluorescent lamps and LED (X axis: wavelength $(\mathrm{nm})$, Y-axis: Irradiance $\left(\mathrm{W} \mathrm{m}^{-2}\right)$ ). 
The spectral irradiance of the different lamps assessed was recorded in Table 3. The addition of LEDs in lamps resulted in an increase of total irradiance in all the lamps assessed except for TLD58-6 lamps. The lamps with the highest total irradiance were TLD58-6 lamps with values around $75 \mathrm{~W} \mathrm{~m}^{-2}$ and with the lowest value were LEDs with values around $3 \mathrm{~W} \mathrm{~m}^{-2}$.

The spectral irradiance in the different regions such as ultraviolet (UV), blue (B), red (R), far-red (FR) and their ratios are very important since they affect the morphogenetic responses of the plant growth under lamps, because plants have evolved other specialized photoreceptors to regulate responses to these physiologically important wavelengths. This region of the light spectrum is well known as morphogenetically active radiation (MAR) [30]. Phytochromes are primarily red-light photoreceptors and distinguish between red and far-red wavelengths to control physiological responses such as seed germination and flowering [31,32]. Cryptochromes, phototropins, and F-box proteins (a specific structural motif associated with signal transduction and regulation of the cell cycle) are blue-light receptors responding to blue/ultraviolet (UV) light wavelengths. Cryptochromes trigger signaling molecules that regulate responses such as circadian rhythms and stem elongation, whereas phototropins control chloroplastic movements to maximize absorption of light $[3,33]$.

Phytochromes and cryptochromes have also been reported to act as green light photoreceptors [34].

The incorporation of blue and red LEDs increased the irradiance in their respective regions ( $R$ and $B$ ) in all the lamps assessed but the use of combination of red and blue (V) LEDs did not show the same results in all the lamps assessed since in TL5-6, TL5-2 and TLD58-2 lamps, the values of B and $\mathrm{R}$ were similar to the values obtained considering the use of red and blue LEDs separately; whereas in TLD18, CF and TLD 58-6 lamps, the values of B and R were different. The use of complementary lighting sources did not generate changes in FR region mainly due to the values of zero found in LEDs. Nevertheless, there was an enrichment in UV region using red and blue LEDs as complementary lighting sources.

Morrow [35] reported that the incorporation of LEDs resulted in an increase in irradiance in their respective regions ( $R$ and $B$ ) mainly due to their energy efficiency and spectral specificity. Nevertheless, the combination of red and blue LEDs did not result in a clear increase of the regions $R$ and $B$ in all the lamps assessed in our experiment which can be due to a possible interaction between the different types of wavelength emitted by each type of LEDs.

Near infrared radiation (NIR) is mainly related to heat and energy balance. Nevertheless, in a culture chamber with light near to the crop, NIR could result in plant overheating and the possibility of damaging tissues [36]. Therefore, the results obtained in LEDs with NIR values of 0 corroborate the high degree of applicability of these lighting systems for seedling plant growth.

As far as PAR was concerned, it was necessary to point out that the results obtained in this experiment revealed that TLD 58-6 lamps showed the highest values of PAR of all the lamps assessed. The use of LEDs separately as a source of lighting provided lower values of PAR around $5 \mathrm{~W} \mathrm{~m}^{-2}$. Considering the different stages analyzed in XTRASUN LEDs, the highest values of PAR were in GG and VG respectively. Moreover, the use of LEDs in combination with the lamps assessed increased the value of PAR except for TLD58-6. Another important feature in light spectrum was the ratio of $\mathrm{PAR} /$ Total in the lamps. In our experiment, the ratio PAR/Total showed the highest value in LEDS and in the stages of VG and FP analyzed in XTRASUN LEDs. The ratios B/R, B/FR and R/FR analyzed in the experiment showed different trends according to the type of lamps assessed.

The PAR (400-700 $\mathrm{nm}$ ) has a higher importance than the other wavebands of the solar spectrum because of its fundamental role in photosynthesis [30]. Therefore, the lamps assessed in our experiment with the highest values of PAR should be the most efficient for the growth of plants mainly due to the role of the PAR in the photosynthetic process. The values of the ratio PAR/Total around 1 in LEDs involves a higher photosynthetic efficiency radiation as reported by Almansa et al. [36]. 
Table 3. Spectral irradiance of the lamps and ratios between different regions of the radiation spectrum.

\begin{tabular}{|c|c|c|c|c|c|c|c|c|c|c|c|c|}
\hline \multirow{2}{*}{ Lamps } & \multicolumn{7}{|c|}{ Irradiance $\left(\mathrm{Wm}^{-2}\right)$ in Spectral Regions } & \multicolumn{5}{|c|}{ Ratios } \\
\hline & UV & B & $\mathbf{R}$ & FR & PAR & NIR & TOTAL & PAR:TOTAL & PAR:NIR & B:R & B:FR & R:FR \\
\hline T1:TLD-18 & 0.12 & 6.52 & 6.80 & 0.58 & 22.66 & 0.92 & 23.74 & 0.95 & 24.63 & 0.96 & 11.24 & 11.72 \\
\hline T2:TLD-18LED-B & 0.16 & 8.00 & 6.78 & 0.58 & 24.22 & 0.90 & 25.28 & 0.96 & 26.91 & 1.18 & 13.79 & 11.68 \\
\hline T3:TLD-18LED-R & 0.16 & 6.36 & 7.88 & 0.56 & 23.48 & 0.88 & 24.52 & 0.96 & 26.68 & 0.81 & 11.35 & 14.07 \\
\hline T4:TLD-18LED-V & 0.16 & 9.00 & 8.68 & 0.54 & 23.56 & 0.86 & 27.58 & 0.96 & 30.88 & 1.04 & 16.66 & 16.07 \\
\hline $\mathrm{T} 5: \mathrm{CF}$ & 0.28 & 5.00 & 6.66 & 0.60 & 20.10 & 0.80 & 20.80 & 0.96 & 25.12 & 0.75 & 8.33 & 11.10 \\
\hline T6:CF-LED-B & 0.32 & 8.26 & 6.66 & 0.68 & 23.84 & 1.16 & 25.34 & 0.94 & 20.50 & 1.24 & 12.12 & 9.76 \\
\hline T7:CF-LED-R & 0.30 & 5.02 & 7.06 & 0.52 & 21.74 & 0.84 & 22.86 & 0.95 & 23.69 & 0.71 & 9.62 & 13.52 \\
\hline T8:CF-LED-V & 0.28 & 6.88 & 7.04 & 0.52 & 21.66 & 0.82 & 22.78 & 0.95 & 26.32 & 0.98 & 13.23 & 13.52 \\
\hline T9:TL5-6 & 0.94 & 10.22 & 19.58 & 1.84 & 49.30 & 2.72 & 52.96 & 0.93 & 18.18 & 0.52 & 5.56 & 10.65 \\
\hline T10:TL5-6-LED-B & 0.92 & 12.94 & 19.86 & 1.78 & 52.74 & 2.34 & 55.98 & 0.94 & 22.62 & 0.65 & 7.27 & 11.15 \\
\hline T11:TL5-6-LED-R & 0.92 & 10.20 & 21.98 & 1.78 & 52.04 & 2.34 & 55.30 & 0.94 & 22.18 & 0.46 & 5.70 & 12.30 \\
\hline T12:TL5-6-LED-V & 0.94 & 12.92 & 22.00 & 1.80 & 54.98 & 2.36 & 58.26 & 0.94 & 23.33 & 0.59 & 7.19 & 12.26 \\
\hline T13:TL5-2 & 0.36 & 4.04 & 7.94 & 0.72 & 19.86 & 0.94 & 21.14 & 0.94 & 21.34 & 0.51 & 5.67 & 11.12 \\
\hline T14:TL5-2-LED-B & 0.36 & 6.82 & 7.94 & 0.72 & 22.80 & 0.94 & 24.08 & 0.95 & 24.50 & 0.86 & 9.57 & 11.14 \\
\hline T15:TL5-2-LED-R & 0.36 & 4.08 & 10.04 & 0.72 & 22.06 & 0.94 & 22.34 & 0.94 & 23.53 & 0.41 & 5.68 & 13.98 \\
\hline T16:TL5-2-LED-V & 0.38 & 6.76 & 10.02 & 0.72 & 24.88 & 0.94 & 26.18 & 0.95 & 26.28 & 0.68 & 9.37 & 13.88 \\
\hline T17:TLD-58-2 & 1.28 & 7.56 & 9.26 & 0.72 & 27.74 & 1.08 & 29.72 & 0.93 & 25.93 & 0.82 & 10.50 & 12.86 \\
\hline T18:TLD-58-2-LED-B & 1.10 & 11.22 & 8.18 & 0.68 & 31.60 & 1.18 & 33.88 & 0.93 & 26.79 & 1.37 & 16.51 & 12.04 \\
\hline T19:TLD-58-2-LED-R & 1.12 & 8.84 & 10.08 & 0.70 & 31.18 & 1.20 & 33.48 & 0.93 & 26.19 & 0.88 & 12.82 & 14.61 \\
\hline T20:TLD-58-2-LED-V & 1.14 & 11.22 & 10.06 & 0.70 & 33.70 & 1.22 & 36.06 & 0.93 & 27.76 & 1.12 & 16.15 & 14.47 \\
\hline T21:TLD-58-6 & 3.28 & 19.42 & 24.60 & 2.00 & 72.24 & 2.98 & 77.70 & 0.93 & 24.21 & 0.79 & 9.69 & 12.27 \\
\hline T22:TLD-58-6-LED-B & 3.18 & 20.94 & 23.18 & 1.84 & 71.08 & 2.68 & 76.12 & 0.93 & 26.60 & 0.90 & 11.42 & 12.64 \\
\hline T23:TLD-58-6-LED-R & 3.08 & 17.96 & 24.42 & 1.78 & 68.74 & 2.60 & 73.56 & 0.93 & 26.46 & 0.74 & 10.07 & 13.68 \\
\hline T24:TLD-58-6-LED-V & 3.12 & 20.34 & 24.02 & 1.78 & 70.62 & 2.60 & 75.46 & 0.94 & 27.20 & 0.85 & 11.48 & 13.56 \\
\hline T25:LED-B & 0.02 & 2.42 & 0 & 0 & 2.56 & 0 & 2.58 & 0.99 & - & - & - & - \\
\hline T26:LED-R & 0.02 & 0 & 1.80 & 0 & 1.82 & 0 & 1.82 & 1 & - & - & - & - \\
\hline T27:LED-V & 0 & 2.34 & 1.74 & 0 & 4.24 & 0 & 4.24 & 1 & - & 1.34 & - & - \\
\hline T28:LED-W & 0.02 & 2.38 & 1.74 & 0 & 5.10 & 0 & 5.10 & 1 & - & 1.37 & - & - \\
\hline $\begin{array}{l}\text { T29:XTRASUN } \\
\text { LED GG }\end{array}$ & 0.02 & 1.45 & 10.87 & 2.25 & 13.06 & 2.71 & 15.44 & 0.85 & 4.83 & 0.13 & 0.64 & 4.83 \\
\hline $\begin{array}{l}\text { T29:XTRASUN } \\
\text { LED VG }\end{array}$ & 0.10 & 8.60 & 3.87 & 0.10 & 12.55 & 0.12 & 12.72 & 0.99 & 107.23 & 2.22 & 90.06 & 40.53 \\
\hline $\begin{array}{c}\text { T29:XTRASUN } \\
\text { LED FP }\end{array}$ & 0.01 & 0.00 & 9.87 & 0.03 & 9.93 & 0.04 & 9.97 & 1.00 & 242.10 & - & 0.03 & 340.19 \\
\hline $\begin{array}{l}\text { T29:XTRASUN } \\
\text { LED UV }\end{array}$ & 0.30 & 3.48 & 2.28 & 0.15 & 9.83 & 0.18 & 10.14 & 0.97 & 54.92 & 1.53 & 23.64 & 15.50 \\
\hline $\begin{array}{l}\text { T29:XTRASUN } \\
\text { LED IR }\end{array}$ & 0.01 & 0.00 & 11.25 & 3.80 & 11.27 & 3.85 & 15.08 & 0.75 & 2.92 & - & - & 2.96 \\
\hline
\end{tabular}




\subsection{Absorbance of Seedlings Plants}

The leaf absorbance from 490 to $700 \mathrm{~nm}$ was slightly higher in the case of cucumber than in tomato seedlings plants although from 700 to $1100 \mathrm{~nm}$ there were no differences in leaf absorbance between both crops. Considering the values of leaf absorbance obtained in our experiment, it can be highlighted that there were different trends taking into account the range of the wavelength studied. For instance, from 490 to $555 \mathrm{~nm}$ there was a clear decline of leaf absorbance reaching values around $65 \%$ but from $555 \mathrm{~nm}$ until $700 \mathrm{~nm}$, leaf absorbance in both crops increased until values of $92 \%$. On the same hand, there was a significant decline in leaf absorbance from 700 to $745 \mathrm{~nm}$ in both crops reaching values of $5 \%$ which remained constant from 745 to $1100 \mathrm{~nm}$ (Figure 3).

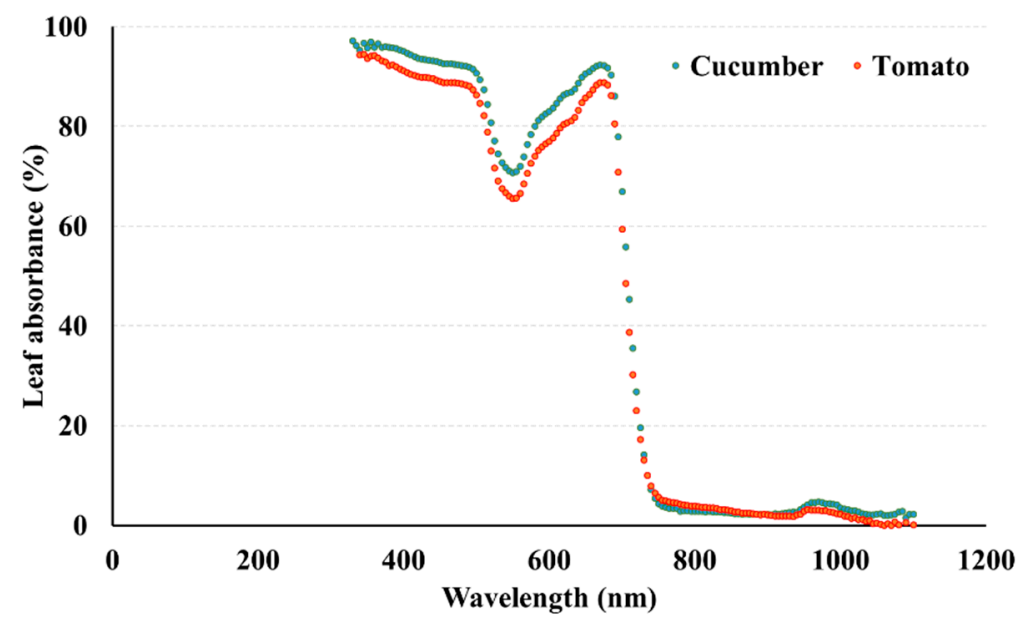

Figure 3. Leaf absorbance expressed in percentage of tomato and cucumber seedling plants.

While reviewing previous literature, we observed that there were references concerning the degree of absorbance in leaves in different crops. For instance, Schurer [37] evaluated this optical parameter in species such as Fuchsia sp., Geranium sp., Hibiscus sp. Similarly, in another experiment, Paradiso et al. [38] evaluated the absorbance of rose leaves reporting a decrease of transmittance and reflectance.

The alteration of spectral properties in leaves in the visible wavelengths can be related to the loss in chlorophyll content. In addition, the arrangement of cells within a leaf can be involved in the increase and/or decrease transmitted light by adjustment of the optical pathlength through the leaf [39].

The effectiveness of light irradiance ELI $_{\text {cucumber }}$ was slightly higher than ELI tomato $_{\text {for all essayed }}$ lamps. The addition of complementary LEDs resulted in an increase of ELI $\mathrm{I}_{\text {plant }}$ in TLD-18, TL5-6 and TL5-2 lamps. TLD-18 lamps and the combination with LEDs showed the lowest values of ELI plant while TL5-6 lamps and the combination with LEDs showed the highest values of ELI $\mathrm{I}_{\text {plant }}$ in both crops. The addition of LEDs in CF lamps only resulted in a significant increase in the UI (expressed in percentage) in both crops. The UI showed the highest values in LEDs in both crops except for white LEDs with values around 35\%. Concerning XTRASUN LED, GG showed the highest values of ELI plant $_{\text {in both }}$ species whereas in VG, UI was found at maximum levels in both crops (Table 4). No references have been found regarding this topic. These results are in accordance with Lin et al. [40] who considered that the use of LEDs could optimize the spectral quality for various plants and different physiological processes, and that they could also create a digitally controlled and energy efficient lighting system. Although the value of VEEI for white LEDs was within the range established by CTE, the UI was really low for both species essayed. Therefore, it is necessary to consider both parameters for the choice of the lamps for their use in horticulture. 
Table 4. Effectiveness of light irradiance $\left(\mathrm{ELI}_{\text {plant }}\right)$ and the use of irradiance (UI) in each species.

\begin{tabular}{|c|c|c|c|c|}
\hline Lamps & $\begin{array}{l}\text { ELI }_{\text {tomato }} \\
\left(\mathrm{Wm}^{-2}\right)\end{array}$ & $\begin{array}{c}\text { ELI }_{\text {cucumber }} \\
\left(\mathrm{Wm}^{-2}\right)\end{array}$ & $\mathrm{UI}_{\text {tomato }}(\%)$ & $\mathrm{UI}_{\text {cucumber }}(\%)$ \\
\hline T1:TLD-18 & 9.38 & 9.52 & 79 & 80 \\
\hline T2:TLD-18LED-B & 10.08 & 10.23 & 80 & 81 \\
\hline T3:TLD-18LED-R & 19.49 & 19.76 & 79 & 81 \\
\hline T4:TLD-18LED-V & 11.16 & 11.33 & 81 & 82 \\
\hline $\mathrm{T} 5: \mathrm{CF}$ & 16.79 & 17.07 & 66 & 67 \\
\hline T6:CF-LED-B & 20.06 & 20.42 & 79 & 81 \\
\hline T7:CF-LED-R & 16.53 & 16.78 & 79 & 80 \\
\hline T8:CF-LED-V & 18.27 & 18.56 & 80 & 81 \\
\hline T9:TL5-6 & 41.34 & 41.94 & 78 & 79 \\
\hline T10:TL5-6-LED-B & 44.33 & 45.01 & 79 & 80 \\
\hline T11:TL5-6-LED-R & 43.65 & 44.26 & 79 & 80 \\
\hline T12:TL5-6-LED-V & 46.28 & 46.96 & 79 & 81 \\
\hline T13:TL5-2 & 16.62 & 16.86 & 79 & 80 \\
\hline T14:TL5-2-LED-B & 19.26 & 19.58 & 80 & 81 \\
\hline T15:TL5-2-LED-R & 18.54 & 18.78 & 79 & 80 \\
\hline T16:TL5-2-LED-V & 21.07 & 21.39 & 80 & 82 \\
\hline T17:TLD-58-2 & 26.77 & 27.19 & 79 & 80 \\
\hline T18:TLD-58-2-LED-B & 26.33 & 26.69 & 79 & 80 \\
\hline T19:TLD-58-2-LED-R & 28.60 & 29.03 & 79 & 81 \\
\hline T20:TLD-58-2-LED-V & 11.80 & 11.96 & 79 & 80 \\
\hline T21:TLD-58-6 & 30.72 & 31.15 & 79 & 80 \\
\hline T22:TLD-58-6-LED-B & 30.29 & 30.73 & 80 & 81 \\
\hline T23:TLD-58-6-LED-R & 29.24 & 29.64 & 80 & 81 \\
\hline T24:TLD-58-6-LED-V & 30.11 & 30.54 & 80 & 81 \\
\hline T25:LED-B & 2.30 & 2.37 & 89 & 92 \\
\hline T26:LED-R & 1.60 & 1.60 & 88 & 88 \\
\hline T27:LED-V & 3.76 & 3.83 & 89 & 91 \\
\hline T28:LED-W & 1.72 & 1.81 & 34 & 35 \\
\hline $\begin{array}{l}\text { T29:XTRASUN } \\
\text { LED GG }\end{array}$ & 11.35 & 12.05 & 73 & 78 \\
\hline $\begin{array}{l}\text { T29:XTRASUN } \\
\text { LED VG }\end{array}$ & 11.19 & 11.69 & 88 & 92 \\
\hline $\begin{array}{c}\text { T29:XTRASUN } \\
\text { LED FP }\end{array}$ & 8.43 & 8.91 & 85 & 89 \\
\hline $\begin{array}{l}\text { T29:XTRASUN } \\
\text { LED UV }\end{array}$ & 8.07 & 8.55 & 80 & 84 \\
\hline $\begin{array}{l}\text { T29:XTRASUN } \\
\text { LED IR }\end{array}$ & 10.16 & 10.69 & 67 & 71 \\
\hline
\end{tabular}

\section{Conclusions}

The previous survey carried out allows us to discern which were the main technical parameters of the artificial lighting systems used in horticultural nurseries in southern Spain as well as the degree of their implementation. The results obtained in this experiment reported that the most efficient systems with a high value of $\eta$ and low value of VEEI were XTRASUNLED and TLD-18 lamps. Regarding the level of irradiance, the lamps with the lowest total irradiance were CF but the combination with LEDs increased the value of the total irradiance. The lamps with the highest values of total irradiance were TLD58-6 lamps and the stage of GG in XTRASUN LEDs. Nevertheless, while considering the use of lamps in seedling production, two parameters have been proposed (ELI plant and $\left.\mathrm{UI}_{\text {plant }}\right)$ relating the power light emission of the lamp with the light absorption by leaves. The effectiveness of light irradiance $\left(\mathrm{ELI}_{\text {plant }}\right)$ was slightly higher in the case of cucumber than that of tomato for all essayed lamps. It can be found in our experiment that LEDs showed the lowest values, while TL5-6 lamps presented the highest values. Nevertheless, the use of irradiance was similar in both species and higher for blue, red, and violet (around 90\%) LEDs, medium for FL and their combinations (around 
80\%) and lower for CF, LEDs-W and XTRASUN LEDs GG and infrared (IR). In this sense, novelty lamps (XTRASUN LEDs) supposed an improvement of the limit value of energy efficiency and the UI for plants as well as a high versatility related to MAR effects. The advantage of artificial lighting systems in nurseries is mainly related to the technological development of this industry that allows nursery growers to produce quality seedling plants in a shorter growing period. Nevertheless, the lack of knowledge among nursery growers concerning the accurate light requirements in horticultural nurseries involves a delay to the implantation of this technology. In this sense, this work shows the current extent of knowledge of artificial lighting systems, showing different alternatives of light sources that can be used in the growth of seedling plants, and the implementation of specific agronomic indexes such as ELI plant and UI to choose the light sources which are more suitable for use in nursery growing systems, ultimately allowing energy saving and the improvement of quality in seedling plants.

Author Contributions: The authors contributed equally to this work.

Funding: This research received no external funding.

Acknowledgments: The authors thank Dimitrios Tsokanos for his English style corrections.

Conflicts of Interest: The authors declare no conflict of interest.

\section{Abbreviations}

The following abbreviations are used in this manuscript:

\begin{tabular}{ll}
$\mathrm{Ab}$ & Absorbance \\
$\mathrm{B}$ & Blue \\
$\mathrm{CF}$ & Compact Fluorescent \\
ELI plant & Effectiveness of light irradiance \\
$\mathrm{FR}$ & Far-Red \\
$\mathrm{FL}$ & Fluorescent Lamps \\
$\mathrm{FP}$ & Flowering Period \\
$\mathrm{GG}$ & General Growth \\
$\mathrm{HPS}$ & High-Pressure Sodium \\
$\mathrm{IR}$ & Infrared radiation \\
$\mathrm{I}$ & Irradiance \\
$\mathrm{E}$ & Light irradiance \\
$\mathrm{VEEI}$ & Limit Value of Energy Efficiency \\
LED & Light-emitting diode \\
$\mathrm{MAR}$ & Morphogenetically Active Radiation \\
$\mathrm{NIR}$ & Near Infrared Radiation \\
$\mathrm{P}$ & Electric Power \\
$\mathrm{PAR}$ & Photosynthetically Active Radiation \\
$\mathrm{R}$ & Red \\
$\mathrm{Re}$ & Reflectance \\
$\mathrm{Tr}$ & Transmittance \\
$\mathrm{UI}$ & Use of Irradiance \\
$\mathrm{UV}$ & Ultraviolet \\
$\mathrm{V}$ & Violet \\
$\mathrm{VG}$ & Vegetative Growth \\
$\mathrm{W}$ & White \\
\hline
\end{tabular}

\section{References}

1. Yang, B.; Zhou, X.; Xu, R.; Wang, J.; Lin, Y.; Pang, J.; Wu, S.; Zhong, F. Comprehensive analysis of photosynthetic characteristics and quality improvement of purple cabbage under different combinations of monochromatic light. Front. Plant Sci. 2016, 7, 1788. [CrossRef] [PubMed] 
2. Kopsell, D.A.; Sams, C.E.; Morrow, R.C. Blue wavelengths from LED lighting increase nutritionally important metabolites in specialty crops. Hortscience 2015, 50, 1285-1288.

3. Christie, J.M. Phototropin blue-light receptors. Annu. Rev. Plant Biol. 2007, 58, 21-45. [CrossRef] [PubMed]

4. Inoue, S.I.; Kinoshita, T.; Matsumoto, M.; Nakayama, K.I.; Doi, M.; Shimazaki, K.I. Blue light-induced autophosphorylation of phototropin is a primary step for signaling. Proc. Natl. Acad. Sci. USA 2008, 105, 5626-5631. [CrossRef] [PubMed]

5. Wang, H.; Gu, M.; Cui, J.; Shi, K.; Zhou, Y.; Yu, J. Effects of light quality on $\mathrm{CO}_{2}$ assimilation, chlorophyll-fluorescence quenching, expression of Calvin cycle genes and carbohydrate accumulation in Cucumis sativus. J. Photochem. Photobiol. B Biol. 2009, 96, 30-37. [CrossRef] [PubMed]

6. Sæbø, A.; Krekling, T.; Appelgren, M. Light quality affects photosynthesis and leaf anatomy of birch plantlets in vitro. Plant Cell Tissue Organ Cult. 1995, 41, 177-185. [CrossRef]

7. Almansa, E.M. Sistema Híbrido de Iluminación para el Desarrollo de Plantas. Aplicación en Invernaderos. Ph.D. Thesis, University of Almería, Almería, Spain, 2011.

8. Bantis, F.; Smirnakou, S.; Ouzounis, T.; Koukounaras, A.; Ntagkas, N.; Radoglou, K. Current status and recent achievements in the field of horticulture with the use of light-emitting diodes (LEDs). Sci. Hortic. 2018, 235, 437-451. [CrossRef]

9. Hernández, R.; Kubota, C. Tomato seedling growth and morphological responses to supplemental LED lighting red:blue ratios under varied daily solar light integrals. Acta Hortic. 2012, 956, 187-194. [CrossRef]

10. Currey, C.J.; Lopez, R.G. Cuttings of Impatiens, Pelargonium, and Petunia propagated under light-emitting diodes and high-pressure sodium lamps have comparable growth, morphology, gas exchange, and post-transplant performance. Hortscience 2013, 48, 428-434.

11. Cocetta, G.; Casciani, D.; Bulgari, R.; Musante, F.; Kołton, A.; Rossi, M.; Ferrante, A. Light use efficiency for vegetables production in protected and indoor environments. Eur. Phys. J. Plus 2017, 132, 43. [CrossRef]

12. Macias, H.A.; Ulianov, Y.; Ramos, Y. Illumination benefits using LED high brightness bulb compare to traditional illumination systems. In Proceedings of the 2012 IEEE International Symposium on Alternative Energies and Energy Quality (SIFAE), Barranquilla, Colombia, 25-26 October 2012; pp. 1-5.

13. Serrano-Tierz, A.; Martínez-Iturbe, A.; Guarddon-Muñoz, O.; Santolaya-Sáenz, J.L. Análisis de ahorro energético en iluminación LED industrial: Un estudio de caso. Dyna 2015, 82, 231-239. [CrossRef]

14. Lim, S.R.; Kang, D.; Ogunseitan, O.A.; Schoenung, J.M. Potential environmental impacts of light-emitting diodes (LEDs): Metallic resources, toxicity, and hazardous waste classification. Environ. Sci. Technol. 2010, 45, 320-327. [CrossRef] [PubMed]

15. ASEHOR (Asociacion de Semilleros Horticolas). 2018. Available online: http://pitalmeria.es/empresas / asehor/ (accessed on 16 August 2018).

16. Almansa, E.M.; Espín, A.; Chica, R.M.; Lao, M.T. Bioassimilation behaviour of tomato seedling cultivars under different sources of artificial light. Aust. J. Crop Sci. 2014, 8, 873-880.

17. Almansa, E.M.; Chica, R.M.; Espín, A.; Lao, M.T. Study on the use of supplementary artificial light in greenhouse production systems in the province of Almeria. Presented at the IV National Congress and I Agronomy Iberian Congress, Albacete, Spain, 2007.

18. Vu, N.T.; Kim, Y.S.; Kang, H.M.; Kim, I.S. Effect of red LEDs during healing and acclimatization process on the survival rate and quality of grafted tomato seedlings. Prot. Hortic. Plant Fact. 2014, 23, 43-49. [CrossRef]

19. Jang, Y.; Mum, B.; Seo, T.; Lee, J.; Oh, S.; Chun, C. Effects of light quality and intensity on the carbon dioxide exchange rate, growth and morphogenesis of grafted pepper transplants during healing and acclimatization. Korean J. Hortic. Sci. Technol. 2013, 31, 14-23. [CrossRef]

20. Hidalgo, A.; Villacrés, L.; Hechavarría, R.; Moya, D. Proposed integration of a photovoltaic solar energy system and energy efficient technologies in the lighting system of the UTA-Ecuador. Energy Proc. 2017, 134, 296-305. [CrossRef]

21. Baille, A.; González-Real, M.M.; López, J.C.; Cabrera, J.; Pérez-Parra, J. Characterization of the solar diffuse component under "Parral" plastic greenhouses. Acta Hortic. 2003, 614, 341-346. [CrossRef]

22. Castilla, N.; Prados, N.C. Invernaderos de Plástico: Tecnología y Manejo; Mundi-Prensa Libros: Madrid, Spain, 2007.

23. Almansa, E.M.; Chica, R.M.; Lao, M.T. Influence of the quality of artificial light on grafting tomato. Aust. J. Crop Sci. 2018, 12, 318-325. [CrossRef] 
24. Spanish Technical Building Code (CTE). Basic Document of Energy Saving (DB-HE). 2006. Available online: http:/ / www.buildup.eu/en/practices / publications/spanish-technical-building-code-royaldecree3142006-17th-march-2006 (accessed on 16 August 2018).

25. Pimputkar, S.; Speck, J.S.; Den Baars, S.P.; Nakamura, S. Prospects for LED lighting. Nat. Photonics 2009, 3, 180-182. [CrossRef]

26. Landis, T.D.; Pinto, J.R.; Dumroese, R.K. Light emitting diodes (LED): Applications in forest and native plant nurseries. For. Nurs. Notes 2013, 33, 5-13.

27. Narukawa, Y.; Ichikawa, M.; Sanga, D.; Sano, M.; Mukai, T. White light emitting diodes with super-high luminous efficacy. J. Phys. D Appl. Phys. 2010, 43, 354002. [CrossRef]

28. Nakamura, S. Nobel lecture background story of the invention of efficient blue InGaN light emitting diodes. Rev. Mod. Phys. 2015, 87, 1139-1151. [CrossRef]

29. Sundström, V. Light in elementary biological reactions. Prog. Quantum Electron. 2000, 24, 187-238. [CrossRef]

30. Pérez, M.; Teixeira da Silva, J.A.; Lao, M.T. Light management in ornamental crops. Floric. Ornam. Plant Biotech. 2006, 4, 683-695.

31. Chaves, I.; Pokorny, R.; Byrdin, M.; Hoang, N.; Ritz, T.; Brettel, K.; Essen, L.O.; van der Horst, G.T.J.; Batschauer, A.; Ahmad, M. The cryptochromes: Blue light photoreceptors in plants and animals. Annu. Rev. Plant Biol. 2011, 62, 335-364. [CrossRef] [PubMed]

32. Fraikin, G.Y.; Strakhovskaya, M.G.; Rubin, A.B. Biological photoreceptors of light-dependent regulatory processes. Biochemistry 2013, 78, 1238-1253. [CrossRef] [PubMed]

33. Briggs, W.R.; Christie, J.M. Phototropins 1 and 2: Versatile plant blue-light receptors. Trends Plant Sci. 2002, 7, 204-210. [CrossRef]

34. Folta, K.M.; Maruhnich, S.M. Green light: A signal to slow down or stop. J. Exp. Bot. 2007, 58, 3099-3111. [CrossRef] [PubMed]

35. Morrow, R.C. LED lighting in horticulture. Hortscience 2008, 43, 1947-1950.

36. Almansa, E.M.; Espín, A.; Chica, R.M.; Lao, M.T. Changes in endogenous auxin concentration in cultivars of tomato seedlings under artificial light. Hortscience 2011, 46, 698-704.

37. Schurer, K. Leaf Absorbance and Photosynthesis. NASA-CP-95-3309. In Proceedings of the International Lighting in Controlled Environments Workshop, Madison, WI, USA, 27-30 March 1994.

38. Paradiso, R.; Meinen, E.; Snel, J.F.; De Visser, P.; Van Ieperen, W.; Hogewoning, S.W.; Marcelis, L.F. Spectral dependence of photosynthesis and light absorptance in single leaves and canopy in rose. Sci. Hortic. 2011, 127, 548-554. [CrossRef]

39. Bauerle, W.L.; Weston, D.J.; Bowden, J.D.; Dudley, J.B.; Toler, J.E. Leaf absorptance of photosynthetically active radiation in relation to chlorophyll meter estimates among woody plant species. Sci. Hortic. 2004, 101, 169-178. [CrossRef]

40. Lin, K.H.; Huang, M.Y.; Huang, W.D.; Hsu, M.H.; Yang, Z.W.; Yang, C.M. The effects of red, blue, and white light-emitting diodes on the growth, development, and edible quality of hidroponically grown lettuce (Lactuca sativa L. var. capitata). Sci. Hortic. 2013, 150, 86-91. [CrossRef]

(c) 2018 by the authors. Licensee MDPI, Basel, Switzerland. This article is an open access article distributed under the terms and conditions of the Creative Commons Attribution (CC BY) license (http:/ / creativecommons.org/licenses/by/4.0/). 